\title{
Laparoscopic Surgery for Ulcerative Colitis
}

\author{
Luca Stocchi, M.D. ${ }^{1}$
}

\section{ABSTRACT}

Laparoscopic techniques have become increasingly used in the treatment of ulcerative colitis: in experienced hands, they are safe and feasible. Recovery advantages have not been consistently demonstrated and functional results have been comparable to open surgery. Other possible benefits and costs issues have also been inconsistent. Further investigation on the role of laparoscopic surgery for ulcerative colitis with larger populations and longer follow-up with a focus on recovery parameters, quality of life, and costs are needed.

KEYWORDS: Laparoscopic surgery, ulcerative colitis, recovery, cosmesis, costs

Objectives: On completion of this article, the reader should be able to summarize the indications and techniques of laparoscopic surgical management of ulcerative colitis.

The surgical management of inflammatory bowel disease has been significantly changed by the advent of laparoscopic techniques. In particular, laparoscopic techniques have become increasingly used in the treatment of ulcerative colitis. Current indications for laparoscopic surgery in the surgical treatment of ulcerative colitis, surgical techniques, and results after laparoscopic surgery, particularly in comparison with open surgery, are evaluated in this review article.

\section{LAPAROSCOPIC SURGERY FOR ACUTE COLITIS}

\section{Indications}

A subgroup of patients with ulcerative colitis requires surgical intervention for acute colitis unresponsive to medical treatment. These patients are generally evaluated in the hospital after maximal medical treatment has failed to improve their symptoms and they have developed either severe or fulminant ulcerative colitis. ${ }^{1,2}$ Under these circumstances, the operation of choice is an initial total abdominal colectomy with creation of an end ileostomy and preservation of the rectum or rectosigmoid stump to reduce postoperative morbidity. In most of these cases, the long-term plan would include recovery from the abdominal colectomy for 3 to 6 months followed by elective completion proctectomy and ileal pouch-anal anastomosis (IPAA). In addition, other candidates for an initial total abdominal colectomy are those patients who are not so acutely ill to require a hospital admission, but have also received prolonged treatment with high doses of steroids and/or other immunosuppressive medications so that they have progressively become anemic or malnourished. In these cases the surgeon might well decide that the general status of the patient is too poor to warrant a total proctocolectomy with ileal pouchanal anastomosis (IPAA). Furthermore, there may be cases where a total abdominal colectomy might be preferable to clarify a possible diagnosis of Crohn disease instead of ulcerative colitis and provide useful information to guide subsequent management and counseling. Recently, some specialized centers have
${ }^{1}$ Department of Colorectal Surgery, Digestive Disease Institute, Cleveland Clinic, Cleveland, Ohio.

Address for correspondence and reprint requests: Luca Stocchi, M.D., Department of Colorectal Surgery, Cleveland Clinic, 9500 Euclid Ave., Desk A31, Cleveland, OH 44195 (e-mail: stocchl@ccf.org).
Ulcerative Colitis; Guest Editor, Feza H. Remzi, M.D.

Clin Colon Rectal Surg 2010;23:248-258. Copyright (C) 2010 by Thieme Medical Publishers, Inc., 333 Seventh Avenue, New York, NY 10001, USA. Tel: +1(212) 584-4662.

DOI: http://dx.doi.org/10.1055/s-0030-1268251.

ISSN 1531-0043. 
proposed that patients requiring surgery for ulcerative colitis who have received treatment with infliximab within the last 3 months preceding surgery should also have an initial total abdominal colectomy without proctectomy as they have reported a significant increase in morbidity after ileal pouch-anal anastomosis performed in patients receiving infliximab. ${ }^{3,4}$ Although this specific contraindication to immediate creation of IPAA remains controversial, ${ }^{5-8}$ it has certainly added to the pool of patients who undergo initial total abdominal colectomy.

In general, the indications for laparoscopic total abdominal colectomy without proctectomy are similar to the established indications for open surgery. In fact, most patients who require an initial total abdominal colectomy are candidates for a laparoscopic approach. However, a subset of patients are not good candidates for laparoscopic total abdominal colectomy, for example, in the case of acute colitis complicated by either colonic perforation or toxic megacolon. Moreover, the patient who is acutely ill with fulminant colitis might still receive better treatment with a more expeditious open abdominal colectomy rather than laparoscopic abdominal colectomy. In particular, if the surgeon feels that the tissues are very friable and are at increased risk of intraabdominal colonic injury during surgical manipulation, he or she might prefer to perform the operation with open technique. In addition, in those rare cases where a Turnbull-Blowhole procedure is considered, such as in pregnant patients, ${ }^{9}$ the open technique remains necessary.

\section{Results of Laparoscopic Surgery for Acute Colitis}

There are no published prospective randomized trials comparing laparoscopic and open total abdominal colectomy for ulcerative colitis. However, several comparative reports have indicated that laparoscopic surgery is safe and feasible in case of acute severe colitis (Table 1).
Reported conversion rates after laparoscopic total abdominal colectomy have been very acceptable, ranging from zero to $8 \% .^{10-16}$

In addition, most series have reported reduced length of hospital stay after laparoscopic procedures when compared with open counterparts (Table 2). The great majority of patients who undergo laparoscopic total abdominal colectomy can undergo subsequent proctectomy and IPAA,${ }^{14,17-19}$ performed either laparoscopically or via a small lower abdominal midline or Pfannenstiel incision, an approach that has been described as "minimal access. ${ }^{18}$ In this respect a laparoscopic Hartmann stump with minimal adhesions could be the ideal setting to initiate a completion proctectomy rather than a longer rectosigmoid stump into the subcutaneous tissue. There is still insufficient data to assess whether a truly laparoscopic restorative proctectomy or a minimal access restorative proctectomy are preferable. In general, a laparoscopic total abdominal colectomy is an effective operation that results in accelerated recovery for patients with acute colitis while retaining comparable morbidity when compared with the open technique. Some of the possible benefits of laparoscopic surgery, such as reduction of pain and cosmesis, have not been formally assessed after total abdominal colectomy, which is generally not the definitive operation for patients with ulcerative colitis. A total abdominal colectomy using a laparoscopic approach may provide advantages in the appropriate patients. However, the natural history of acute ulcerative colitis makes patient selection for laparoscopic surgery paramount to minimize potentially fatal complications in this often very morbid patient population.

\section{Elective Surgical Management of Ulcerative Colitis}

Surgical options for elective management of ulcerative colitis include total proctocolectomy with creation of an end ileostomy, total proctocolectomy with continent

Table 1 Selected Contemporary Series* Comparing Perioperative Morbidity of Laparoscopic versus Open Total Abdominal Colectomy for Acute Ulcerative Colitis

\begin{tabular}{|c|c|c|c|c|c|c|}
\hline Author & Year & $\begin{array}{l}\text { Open/ } \\
\text { Laparoscopic } \\
\text { Patients }\end{array}$ & $\begin{array}{l}\text { Laparoscopic } \\
\text { Technique Used }\end{array}$ & $\begin{array}{l}\text { Morbidity } \\
\text { after Open } \\
\text { Surgery }(\%)\end{array}$ & $\begin{array}{l}\text { Morbidity after } \\
\text { Laparoscopic } \\
\text { Surgery }(\%)\end{array}$ & $P$ Value \\
\hline Dunker et al ${ }^{10}$ & 2000 & $32 / 10$ & Mixed (2 HALS) & 75 & 60 & $0.13 / 0.71$ \\
\hline Marcello et al ${ }^{11}$ & 2001 & $29 / 19$ & Standard & 24 & 16 & NA \\
\hline Seshadri et al ${ }^{12}$ & 2001 & $36 / 37$ & Standard & 44 & 24 & NS \\
\hline Marceau et al ${ }^{13}$ & 2007 & $48 / 40$ & Standard & 56 & 35 & $>.1$ \\
\hline Ouaïssi et al ${ }^{14}$ & 2008 & $22 / 23$ & Standard & 45.5 & 34.8 & NS \\
\hline Watanabe et $\mathrm{al}^{15}$ & 2009 & $30 / 30$ & HALS & 63 & 37 & 0.041 \\
\hline Telem et al ${ }^{16}$ & 2010 & $61 / 29$ & Standard & 34 & 28 & NS \\
\hline
\end{tabular}

* $\geq$ Year 2000, $\geq 10$ patients/group.

HALLS, Hand-assisted laparoscopic surgery; NA, not applicable; NS, nonsignificant.

Note: Dunker et al includes 2 and 5 patients with Crohn's disease in the laparoscopic and open groups, respectively. Morbidity was recalculated and was originally reported divided into minor and major complications with $p$ values of 0.13 and 0.17 , respectively. Seshadri et al includes 6 and 10 cases of Crohn's disease for laparoscopic and open surgery, respectively. 
Table 2 Contemporary Selected Series* Comparing Recovery Parameters Following Laparoscopic versus Open Total Abdominal Colectomy for Acute Ulcerative Colitis

\begin{tabular}{|c|c|c|c|c|c|c|}
\hline Author & Year & $\begin{array}{l}\text { Open/ } \\
\text { Laparoscopic } \\
\text { Patients }\end{array}$ & $\begin{array}{l}\text { Open/Laparoscopic } \\
\text { Return to Bowel } \\
\text { Function }\end{array}$ & $P$ Value & $\begin{array}{l}\text { Open/Laparoscopic } \\
\text { LOS }\end{array}$ & $P$ Value \\
\hline Marcello et $a^{11}$ & 2001 & 29/19 & $2 / 1$ & 0.003 & $6 / 4$ & 0.04 \\
\hline Seshadri et al $^{12}$ & 2001 & $36 / 37$ & NA & NA & $9 / 6$ & 0.001 \\
\hline Marceau et al ${ }^{13}$ & 2007 & $48 / 40$ & NA & NA & $12 / 9$ & $<.10$ \\
\hline Ouaïssi et al ${ }^{14}$ & 2008 & $22 / 23$ & NA & NA & 13/9.3 & 0.032 \\
\hline Watanabe et al ${ }^{15}$ & 2009 & $30 / 30$ & NA & NA & $33 / 23$ & 0.041 \\
\hline Telem et al ${ }^{16}$ & 2010 & $61 / 29$ & NA & NA & $6 / 4.5$ 14.4/10.3 & $<0.001 \mathrm{NS}$ \\
\hline
\end{tabular}

* $\geq$ Year $2000, \geq 10$ patients/group.

HALS, Hand-assisted laparoscopic surgery; LOS, length of hospital stay.

Note: Data are reported as mean except in the studies by Marcello, Seshadri, and Watanabe, which report median values. Telem et al reported separately the length of hospital stay for patients with postoperative complications and without complications $(p<0.001)$. In Ouaïssi et al the mean length of hospital stay also includes hospitalization for complications. Reports from Marceau et al and Ouaïssi et al come from the same institution.

ileostomy, total proctocolectomy with IPAA, and total abdominal colectomy with ileorectal anastomosis. Among these, a creation of an IPAA is currently considered the preferred standard of care. Patients who are not suitable candidates for IPAA can be treated with laparoscopic total proctocolectomy and end ileostomy. On the other hand, laparoscopic surgery in the creation of an ileorectal anastomosis following total abdominal colectomy is technically feasible, but is rarely indicated. ${ }^{20}$ Similarly, total proctocolectomy and creation of a continent ileostomy is generally performed on patients who had previous surgical procedures for ulcerative colitis and is therefore typically performed using open technique. Ileorectal anastomosis and continent ileostomy will therefore not be further discussed in this review.

\section{What Really Constitutes Laparoscopic IPAA? Variability within the Same Definition}

A variety of techniques is currently referred to as "laparoscopic IPAA." In some cases, the dissection of the rectum and the transection at the anorectal ring are performed using standard laparoscopic techniques. The specimen is then removed through either a small lower midline incision, a Pfannenstiel incision, or through the site where a subsequent diverting loop ileostomy will be created. ${ }^{21}$ Some surgeons perform a completely laparoscopic rectal dissection, but prefer to transect the distal rectum through the extraction site using a conventional linear stapler. ${ }^{22}$ In other cases, the rectal dissection is not performed laparoscopically, rather it is performed under direct vision using the future extraction site and following complete laparoscopic mobilization of the abdominal colon.

A possible alternative to standard laparoscopic techniques is the use of hand-assist devices. ${ }^{17,23}$ In fact, evidence from a prospective randomized trial indicates that hand-assist devices can be useful reducing operative times while maintaining the morbidity and recovery benefits of standard laparoscopic techniques in colorectal surgery. ${ }^{24}$ More specifically, there is evidence from comparative studies of the advantages of handassisted technique for laparoscopic IPAA. ${ }^{25}$ Although increasingly accepted for intraabdominal colonic dissection, especially in obese patients, many surgeons still view the intracorporeal hand as poorly suitable for the restricted spaces of a pelvic dissection, so that a portion or the entire rectal dissection is again performed through the Pfannenstiel incision used to insert the hand-assist device used for the laparoscopic colonic dissection. In some cases, the specimen held under tension through the opening of the hand-assist device may facilitate rectal exposure for a standard laparoscopic rectal dissection. As different combinations of these various dissection and transection techniques are reported, it is more difficult to objectively evaluate the data from laparoscopic IPAA as a whole when compared with the open technique.

\section{Surgical Techniques}

Several different laparoscopic surgical techniques have been described in the treatment of ulcerative colitis. ${ }^{23,25-}$ 29 The feasibility of laparoscopic IPAA has been reported in the case of synchronous primary sclerosing cholangitis $^{30}$ and in patients who have undergone liver transplantation. $^{31}$

In this section, we describe the technique commonly used in our unit for the dissection of the abdominal colon and the rectum, respectively, with reconstruction of the intestinal continuity using IPAA.

\section{Laparoscopic Total Abdominal Colectomy}

The patient is positioned in a modified lithotomy position and the chest is strapped to the operating table prior to prepping and draping of the patient. Alternatively, an inflatable "bean bag" can be used to minimize 
the possibility of patient sliding during the change in patient positioning.

The surgical approach using standard laparoscopic techniques requires initial creation of pneumoperitoneum, generally at 12 to $14 \mathrm{~mm} \mathrm{Hg}$. We generally use 4 ports. One supraumbilical midline 10-mm Hasson cannula is placed initially and then pneumoperitoneum is established. Additionally, a 5- $\mathrm{mm}$ port is placed in the left lower quadrant or at the left interclavicular line along the transverse umbilical line depending on the size of the patient, a $12-\mathrm{mm}$ port site in the right lower quadrant or at the right interclavicular line along the transverse umbilical line, and an additional $12-\mathrm{mm}$ port located 2 to 3 fingerbreadths cephalad to the pubic bone and $2 \mathrm{~cm}$ to the right of the midline. The latter port is generally used to perform most of the laparoscopic rectal dissection and to place the endostapler for transection at the anorectal ring in case a total proctocolectomy is performed at once. When a hand-assisted approach is instead used, the disposition of the port sites vary slightly and the procedure begins with placement of a handassist device through a Pfannenstiel incision, which generally ranges from 6 to $8 \mathrm{~cm}$ depending on the hand size of the main operator. In this case, 3 additional ports are used that are placed similarly to what has been described as the straight laparoscopic approach.

The dissection can be performed in a lateral to medial fashion or in a medial to lateral fashion and we generally prefer the latter. Following laparoscopic visualization of the liver and the rest of the abdomen to rule out metastatic or other unsuspected disease, the colonic dissection generally begins with identification and takedown of the ileocolic vascular pedicle, which facilitates the exposure and preservation of the underlying second and third portions of the duodenum. In the presence of ulcerative colitis associated with biopsy-proven carcinoma or dysplasia with or without DALM (dysplasiaassociated lesion or mass), the lymphovascular pedicles should be taken at their origins, which is otherwise not necessary in benign inflammatory disease. The right ureter may also be visible at this time, but its identification is not as critical as the identification of the left ureter during mobilization of the left colon. We find that a steep Trendelenburg and left tilted position is very helpful in a lateral to medial dissection and while taking the lateral attachments of the right colon and retroperitoneal attachments of the terminal ileum. However, this is not necessarily the case when working on the ileocolic lymphovascular pedicle in a medial-to-lateral dissection. The medial dissection is performed caudad-to-cephalad to expose the undersurface of the proximal transverse colon and the gallbladder. The posterior attachments of the ascending colon and a portion of the hepatic flexure can also be taken down during the medial portion of the dissection. The subsequent takedown of the lateral and superior attachments allows complete medialization of the right colon. A reverse Trendelenburg position is generally preferable for mobilization of the hepatic flexure, especially in heavier patients.

With respect to the technique of vessel ligation, we have progressively transitioned from the use of laparoscopic vascular staplers to exclusive use of tissuesealing devices. We find them less expensive and at least as safe and practical as the systematic use of vascular staplers. Following complete mobilization of the right colon, it is generally possible to identify the right edge of the omentum, the first three portions of the duodenum, the head of the pancreas, and the right edge of the transverse mesocolon. At this stage, it is possible to take down the right and left branches of the middle colic artery using a tissue-sealing device or, if necessary, identify and similarly take down more proximally the short trunk of the middle colic artery near the pancreas. Preservation of the omentum is left to the discretion of the operating surgeon. If the omentum is taken along with the specimen, it is possible to take it together with the transverse mesocolon. The takedown of the omentum and transverse mesocolon is continued using a tissue-sealing device from right to left until the splenic flexure is reached. In some cases, it is possible to take down the splenic flexure from cephalad to caudad in continuity with the transverse colon dissection, which is typically performed in a reverse Trendelenburg position. In other, more complex cases, a combined approach including mobilization of the proximal descending colon in a retrograde fashion after tilting the table to the right may become necessary to complete mobilization of the splenic flexure. Following that, the patient position is reversed to Trendelenburg and the inferior mesenteric artery/superior rectal artery pedicle is identified. If the operation to be performed is a total abdominal colectomy and there are no oncologic concerns, we favor preservation of the superior rectal artery. In this case, we mobilize the sigmoid colon from lateral to medial and identify the sigmoidal arteries and take them down as needed.

At this stage, the decision is made whether to transect the rectum as a Hartmann stump or leave a longer rectosigmoid stump to be brought in the subcutaneous tissue of the extraction site. This depends on the specific indications for surgery and the quality of the tissues, which is assessed intraoperatively. For example, when acute colitis in a malnourished patient is often associated with severely inflamed, friable tissues, we preferentially leave the stapled rectosigmoid in the subcutaneous tissue. Some surgeons routinely avoid creation of a Hartmann stump in all cases of acute colitis. A possible advantage of a Hartmann stump may be facilitation of subsequent laparoscopic completion proctectomy. In fact, although the identification of a Hartmann stump after open total abdominal colectomy can often be challenging due to the severity of the adhesions, in the patient treated with laparoscopic 
surgery there are frequently only minimal intraabdominal adhesions. In any case, we avoid entering the presacral space at this time. Once the transection site is decided, we generally proceed to takedown of the surrounding mesocolic tissue with tissue-sealing devices and bowel transection using endoGIA $60 \mathrm{~mm}$. We then complete the mesocolic takedown in a retrograde fashion also using an energy delivery device from the level of bowel transaction in a cephalad direction until we join the proximal mesocolic edge near the mobilized splenic flexure.

It is also possible to perform the rectal or rectosigmoid transection after complete devascularization and exteriorization of the specimen by placing a linear stapler through the extraction site. This is our preference in those cases where the rectosigmoid is placed subcutaneously. We routinely check that the entire colon and terminal ileum lie anteriorly to the remainder of the small bowel prior to exteriorization. The exteriorization site can be a small Pfannenstiel or vertical lower midline incision and we routinely place a small wound protector prior to exteriorization. Before removing the specimen from the field, we check again to ensure the appropriate mesenteric orientation of the exteriorized terminal ileum, which we then transect and prepare for the creation of a terminal ileostomy. The specimen is then removed from the field, the stoma aperture created in the premarked site, typically on the right, and the appropriately oriented terminal ileum passed. If the operation has proceeded smoothly, we generally start closing the abdominal incisions at this time without repeat laparoscopy. A large Malecot drain is placed transanally into the rectum to facilitate decompression of the newly fashioned transection line.

\section{Rectal Dissection and lleal-Pouch Anal Anastomosis}

If the planned operation is a total proctocolectomy no transection is performed at the level of the rectum or sigmoid. Instead, the superior rectal artery is taken down close to the rectum which can facilitate access to the presacral space. When a completion proctectomy is performed, there may be filmy adhesions with some loops of small bowel, which are typically limited and can be taken down laparoscopically. When the initial colectomy was performed laparoscopically, we often note minimal or no adhesions in this area. In particular, if a Hartmann stump has been previously created, a completion proctectomy can begin laparoscopically using the same port-sites previously selected for the abdominal colectomy. On the other hand, in those cases when the rectosigmoid stump was brought to the subcutaneous tissue, it is necessary to begin a completion proctectomy with mobilization of the colorectal segment using the existing extraction site in- cision. Once the bowel is mobilized and replaced inside the abdominal cavity, pneumoperitoneum can then be established. A takedown of the inferior mesenteric near its origin is advisable when oncologic concerns are an issue as described above. It is possible to mobilize the rectum circumferentially all the way down to the pelvic floor using a completely laparoscopic technique and in this case, we generally prefer using the tissue-sealing devices. However, other surgeons contend that laparoscopic mobilization with electrocautery or scissors allows a more accurate identification of the anatomical planes. It is also technically possible to do an intramesorectal dissection of the rectum, although we believe that an appropriate, nerve-sparing complete mesorectal excision with the use of the above-mentioned instruments is feasible in a most cases and can accomplish the same functional results with respect to sexual and urinary function.

We generally attempt to tailor the mesorectal excision so that the lateral dissection is performed closer to the rectal wall than to the pelvic sidewalls to minimize the risk of nerve injury at this level. The anterior dissection is typically performed after posterior and lateral mobilization. Unless the patient has an anterior rectal carcinoma, we routinely preserve the Denonvilliers fascia. An appropriately completed rectal dissection to the level of the levators should expose the distal rectum as a tubular intestinal structure not covered by mesorectum or other fat at the level of the anorectal ring. At that time, the transection at the level of the anorectal ring is performed using a reticulating endostapler passed through the suprapubic port site. The tip of a finger placed in the anus with the proximal interphalangeal joint at the level of the anal verge provides a useful estimate of the appropriate level of transection that requires appropriate adjustment based on the gender and body habitus of the individual patient. This assessment is not different from what is required in the open technique. However, the specific orientation of the laparoscopic staple line is not such a critical factor, provided an intact staple line is placed at the appropriate level of the anorectal ring. For example, an anteroposterior orientation does not compromise the integrity of the subsequent IPAA and may well be the best technical option depending on the exposure for the laparoscopic stapler in the deep pelvis.

We try to optimize the distal rectal dissection so that no more than two cartridges are required for distal transection as there is some data indicating that this could increase the incidence of anastomotic leak. ${ }^{32}$ Following complete mobilization the colon and rectum the specimen is exteriorized by enlarging the suprapubic port into a 4- to $5-\mathrm{cm}$ transverse Pfannenstiel incision. Generally, the abdominal fascia is also incised transversely so that cephalad and caudad fascial flaps 
can be developed, and the underlying rectus muscle entered along the midline with a muscle-splitting incision. We prefer to enter the peritoneal cavity using the most cephalad portion of this midline access to minimize the risk of bladder injury. We then place a wound protector and remove the entire specimen in continuity with the terminal ileum. Alternatively, a traditional linear stapler can be placed through the extraction site to transect the rectum at the level of the anorectal ring instead of using a laparoscopic stapler.

Once the specimen is exteriorized, we take down the endileostomy, if there is one, perform transection at the terminal ileum, and construct a $15-$ to $20-\mathrm{cm}$ ileal Jpouch using 2 cartridges of ILA 100, similar to the open technique. Some surgeons reinforce the blind loop of the pouch with transfixing or imbricating sutures of reabsorbable material. The anvil of the circular stapler is then placed in the distal, lateral opening of the ileum used to create the J-pouch and secured with a purse string suture. Pneumoperitoneum is then reestablished by replacing the port through the wound protector at the extraction site and temporarily reapproximating the skin defect with towel clips. The pin of the circular stapler is advanced through the anorectal ring under laparoscopic vision in preparation for a stapled anastomosis. Similar to the open technique, it is important to ensure that the shaft of the stapler is passed proximal to the level of the sphincter mechanism and gentle pressure is exerted by the instrument against the anorectal staple line before deploying the pin to minimize the risk of staple line disruption.

Particular care should be used in opening the stapler in a female patient so that the pin is passed through the posterior portion of the anorectal ring to minimize the risk of including a portion of the vagina in the stapled IPAA thus causing an iatrogenic pouchvaginal fistula. The progressive closure of the stapler may be monitored laparoscopically to ensure appropriate apposition of the 2 anastomotic segments. At this stage in female patients a laparoscopic grasper can be used to push the vagina anteriorly and out of harm's way. According to some surgeons, this particular portion of the laparoscopic operation offers improved exposure when compared with its open counterpart. Once the firing of the staple is completed and the instrument removed, the anastomotic doughnuts are checked and an air-leak test performed as it is typically done in the open technique.

A loop of bowel is then selected to create a proximal diverting loop ileostomy, which is generally fashioned at the time of the IPAA as for most patients after open technique. At this time we routinely place a drain in the presacral space, which is exited through the left-sided 5-mm port-site and secured to the skin after removal of the port. Pneumoperitoneum is then again evacuated and the final selection and orientation of the adequate ileal loop for the creation of a proximal diverting ileostomy is finalized through the extraction site. We generally orient the ileal loop under direct vision through the extraction site, wrap it with a hyaluronate-based membrane (Seprafilm ${ }^{\mathbb{R}}$, Genzyme Corp., Cambridge, MA), and pass through the stoma aperture. It is generally possible to ensure the orientation of the ileostomy through the extraction site. However, in those cases in which the anatomy is more difficult, it is possible to reestablish pneumoperitoneum at this time and control the orientation of the ileostomy loop laparoscopically. Following that, we close the fascia of the extraction site and the $10-\mathrm{mm}$ and $12-\mathrm{mm}$ port sites. We do not routinely close the fascia of $5-\mathrm{mm}$ port-sites. We also generally do not use the ileostomy site for a port placement, but this is a possible option in a patient with a suitable anatomy.

\section{PERIOPERATIVE RESULTS OF LAPAROSCOPIC IPAA}

Most data on laparoscopic IPAA comes from nonrandomized studies. The great majority of reports concur that IPAA performed laparoscopically is associated with longer operative times than their open counterparts. However, few series have reported comparable operative times. ${ }^{14,22,33}$ Similarly, most series also indicate a reduction in estimated blood loss following a laparoscopic versus open IPAA. ${ }^{26,33,34}$ However, the clinical significance of such a reduction remains questionable. Conversion rates of laparoscopic IPAA have been generally lower than what is reported for laparoscopic colectomy for cancer, ranging from zero to $11 \% .^{21,26,34-41}$ Morbidity following laparoscopic versus open IPAA has been similar (Table 3). In addition, the studies reporting on readmission rates have also found no difference between laparoscopic and open IPAA. ${ }^{36,42}$

Postoperative advantages attributed to the laparoscopic approach also include an accelerated postoperative recovery. In particular, several series have reported more rapid return to bowel function after laparoscopic procedures, which has been generally associated with a correspondingly reduced length of hospital stay (Table 4). However, there have been trials in which the reduction in time to bowel function after laparoscopic IPAA has not uniformly resulted in a corresponding shorter hospital stay. ${ }^{22,33,42}$ As different surgeons often selectively perform laparoscopic or open surgery, it is possible that variability in postoperative care pathways might explain at least some of the results reported in the various studies. Future investigation will need to focus on objective recovery parameters with uniform and welldefined postoperative management so that the expected advantages in recovery after laparoscopic surgery will be elucidated. 
Table 3 Selected Contemporary Series* Comparing Morbidity of Laparoscopic versus Open IPAA for Ulcerative Colitis

\begin{tabular}{|c|c|c|c|c|c|c|}
\hline Author & Year & $\begin{array}{l}\text { Open/ } \\
\text { Laparoscopic } \\
\text { Patients }\end{array}$ & Laparoscopic Technique Used & $\begin{array}{l}\text { Morbidity } \\
\text { after Open } \\
\text { Surgery }(\%)\end{array}$ & $\begin{array}{l}\text { Morbidity after } \\
\text { Laparoscopic } \\
\text { Surgery }(\%)\end{array}$ & $P$ Value \\
\hline Marcello et al ${ }^{26}$ & 2000 & $20 / 20$ & Standard & 25 & 20 & NA \\
\hline Araki et al ${ }^{33}$ & 2001 & $11 / 21$ & $\begin{array}{l}\text { Standard laparoscopic abdominal } \\
\text { colectomy, open rectal dissection }\end{array}$ & 45.5 & 33.3 & NS \\
\hline Brown et al ${ }^{35}$ & 2001 & $13 / 12$ & Standard & 15.4 & 16.7 & NS \\
\hline Hashimoto et al ${ }^{34}$ & 2001 & $13 / 11$ & $\begin{array}{l}\text { Standard laparoscopic abdominal } \\
\text { colectomy, open rectal dissection }\end{array}$ & 38.5 & 54.5 & NA \\
\hline Maartense et $\mathrm{al}^{42}$ & 2004 & $30 / 30$ & HALS & 20 & 23.3 & NS \\
\hline Larson et $\mathrm{al}^{36}$ & 2006 & $200 / 100$ & Mixed (23 HALS) & 37 & 33 & 0.55 \\
\hline Zhang et $\mathrm{al}^{38}$ & 2007 & $25 / 21$ & Standard & 28 & 23.8 & NS \\
\hline Heise et $\mathrm{al}^{39}$ & 2008 & $91 / 60$ & $\begin{array}{l}\text { Straight laparoscopic abdominal } \\
\text { colectomy, open rectal dissection }\end{array}$ & NA & 10.8 & NA \\
\hline Ouaïssi et $\mathrm{al}^{14}$ & 2008 & $22 / 23$ & Standard & 45.5 & 65.2 & NS \\
\hline El Gazzaz et al ${ }^{41}$ & 2009 & $238 / 119$ & Mixed (9 HALS) & 21.5 & 23.1 & 0.091 \\
\hline Fichera et $\mathrm{al}^{22}$ & 2009 & $106 / 73$ & Standard & 41.2 & 48 & NS \\
\hline
\end{tabular}

* $\geq$ Year $2000, \geq 10$ patients/group.

IPAA, Ileal pouch-anal anastomosis; HALS, hand-assisted laparoscopic surgery.

Note: The series of Marcello et al, Larson et al, and Heise et al include 14, 2, and 5 patients with familial adenomatous polyposis, respectively. In Ouaïssi et al, Hashimoto et al, and Fichera et al the morbidity was recalculated, specific overall P values not reported.

Table 4 Contemporary Selected Series* Comparing Recovery Parameters Following Laparoscopic versus Open IPAA for Ulcerative Colitis

\begin{tabular}{|c|c|c|c|c|c|c|}
\hline Author & Year & $\begin{array}{l}\text { Open/ } \\
\text { Laparoscopic } \\
\text { Patients }\end{array}$ & $\begin{array}{l}\text { Open/Laparoscopic } \\
\text { Return to Bowel } \\
\text { Function }\end{array}$ & $P$ Value & $\begin{array}{l}\text { Open/ } \\
\text { Laparoscopic } \\
\text { LOS }\end{array}$ & $P$ Value \\
\hline Marcello et $a^{26^{*}}$ & 2000 & $20 / 20$ & $4 / 2$ & 0.03 & $8 / 7$ & 0.02 \\
\hline Araki et $\mathrm{al}^{33}$ & 2001 & $11 / 21$ & $5.4 / 1.7$ & $<0.05$ & $39 / 36$ & NS \\
\hline Brown et $a^{35}$ & 2001 & $13 / 12$ & $3 / 3$ & NS & $8 / 7.5$ & NS \\
\hline Hashimoto, 2001 et al ${ }^{34}$ & 2001 & $13 / 11$ & $4.3 / 3.6$ & NS & $31.3 / 24.9$ & $<0.05$ \\
\hline Maartense et $\mathrm{al}^{42}$ & 2004 & $30 / 30$ & NA & NA & $11 / 10$ & NS \\
\hline Larson et al ${ }^{36^{*}}$ & 2006 & $200 / 100$ & $3 / 2$ & 0.017 & $7 / 4$ & $<0.001$ \\
\hline Zhang et $\mathrm{al}^{38}$ & 2007 & $25 / 21$ & $4 / 2$ & $<0.001$ & $11 / 9$ & $<0.001$ \\
\hline Heise et $a^{39^{*}}$ & 2008 & $91 / 60$ & $4.5 / 3.6$ & 0.04 & $8.2 / 6.3$ & $<0.001$ \\
\hline Ouaïssi et al $^{14}$ & 2008 & $22 / 23$ & NA & NA & $19 / 13$ & NS \\
\hline El Gazzaz et al ${ }^{41}$ & 2009 & $238 / 119$ & $3 / 2$ & 0.001 & $6 / 5$ & 0.001 \\
\hline Fichera et $\mathrm{al}^{22}$ & 2009 & $106 / 73$ & $3.6 / 2.6$ & 0.008 & $7.4 / 8.3$ & 0.135 \\
\hline
\end{tabular}

* $\geq$ Year $2000, \geq 10$ patients/group.

IPAA, lleal pouch-anal anastomosis; LOS, length of hospital stay.

Note: Studies report median values except for Araki et al, Heise et al, Ouaïssi et al, and Fichera et al, which report mean values. Hashimoto et al reported return to bowel function as "duration of postoperative prohibition from eating." The series of Marcello et al, Larson et al, and Heise et al include 14, 2, and 5, patients with familial adenomatous polyposis, respectively.

\section{FUNCTIONAL RESULTS, COSMESIS, AND BODY IMAGE}

As an increasing number of studies has confirmed the feasibility and safety of laparoscopic IPAA, the focus of investigators has started shifting toward evaluation of possible functional benefits of laparoscopic IPAA. In particular, one aspect of functional evaluations has consisted of prospective collection on data concerning defecatory function, such as number of daily and nightly bowel movements, stool consistency, incidence of fecal incontinence, fecal soilage and need for pad usage, similar to what has been traditionally done for open IPAA. In addition, formal evaluation of quality of life has also been performed, often using validated questionnaires in the attempt to assess whether a minimally invasive technique achieved superior benefits when compared with open IPAA. Few studies have evaluated these outcomes and they are difficult to compare as they have used different methodologies. The evaluation of functional defecatory parameters in two case-matched series has revealed similar overall results between patients undergoing laparoscopic IPAA versus open IPAA. ${ }^{41,43}$ 
Other comparative studies have confirmed substantial equivalence between the two techniques in this regard. ${ }^{14,22,41,44}$ However, in some specific areas, laparoscopic surgery has been associated with improved functional results when compared with open technique. For example, one series has indicated that dietary restrictions were less common after laparoscopic surgery rather than open surgery. ${ }^{44}$ In addition, another study has indicated that laparoscopic surgery was associated with an increased incidence of pasty rather than liquid bowel movements and a decreased incidence of perianal rash. ${ }^{22}$ Two different studies have reported a decreased frequency of pad usage. ${ }^{22,41}$ With respect to sexual function, body image, and quality of life, the overall results have also been comparable. ${ }^{42,44,45}$ One study has however reported lower scores in the specific domain of orgasmic function scores in men undergoing laparoscopic IPAA. ${ }^{45}$ In this respect, it is important to note that the comparison in this specific domain revealed a statistically significant disparity in outcomes, but the actual difference amounted to less than one point $(9.2$ vs 9.9) using a validated sexual function score. The statistical results might therefore not be associated with a corresponding clinically relevant difference, especially considering that the overall function was rated as comparable in both men and women. The outcomes regarding cosmesis have been variable. Although one study from Europe has detected significantly better cosmetic satisfaction after laparoscopic surgery, ${ }^{44}$ evaluation of cosmesis was comparable in a different analysis from the United States. ${ }^{45}$ Body image and quality of life were also comparable in this study. It is noticeable that in the European study the main incision length for laparoscopic-assisted procedures was $15 \mathrm{~cm}$ as opposed to a mean length of incision of almost $24 \mathrm{~cm}$ for conventional IPAA. A recent study has addressed the perceived issue of possible differences between a hand-assisted laparoscopic IPAA and the standard of the total laparoscopic IPAA. In this analysis, 35 patients ${ }^{46}$ undergoing standard laparoscopic IPAA were compared with the patients previously enrolled in a prospective randomized trial that had compared hand-assisted laparoscopic IPAA and open IPAA. ${ }^{42}$ Results from this study did not suggest any significant benefits in quality of life when compared with the hand-assisted laparoscopic restorative proctocolectomy.

It is important to point out that both in casematched studies and especially in purely retrospective analyses, patient selection could explain at least some of the differences in favor of laparoscopic IPAA. The evidence to date suggests that there might be some functional and quality of life benefits associated with laparoscopic IPAA. However, the consistency and relevance of these benefits remains questionable and will require further evaluation with longer followup.

\section{OTHER POSSIBLE ADVANTAGES OF LAPAROSCOPIC IPAA}

Anticipated long-term advantages in favor of laparoscopic restorative proctocolectomy should include reduction in the formation of abdominal and pelvic adhesions, ${ }^{47-49}$ which in turn could lead to reduction in the incidence of small bowel obstruction and incisional hernias. ${ }^{22,50,51}$ These are possible longer-term advantages in favor of laparoscopic surgery which reflect what has been suggested for laparoscopic intestinal resection in general. More specifically, a distinctive advantage of laparoscopic restorative proctocolectomy derived from an allegedly decreased pelvic scarring could be increased fecundity, which is adversely affected by open IPAA ${ }^{52}$ in the often young, female patients. This is an issue which remains difficult to evaluate, especially considering the heterogeneity of the techniques collectively referred as "laparoscopic IPAA," as previously discussed. The specific technique of rectal dissection might have a considerable influence on fecundity, but there is currently no data that can indicate if any of the different minimally invasive techniques can increase fecundity compared with open IPAA. Only long-term data for each specific laparoscopic surgical technique will possibly bring some clarity in this already controversial issue.

As laparoscopic IPAA results in longer operative times but shorter hospital stay in several series, it is possible that the accelerated recovery might offset the increased operative costs and results in a less invasive but also less expensive surgical approach. Little data are available on costs after laparoscopic versus open IPAA, but at this time there does not seem to be a significant difference between the two techniques. ${ }^{39,42}$

\section{PROSPECTIVE RANDOMIZED TRIALS EVALUATING LAPAROSCOPIC IPAA}

There is only one prospective randomized trial comparing laparoscopic and open techniques for restorative proctocoletomy $^{42}$ published to date. Sixty patients were randomized into 2 equal groups undergoing open IPAA versus hand-assisted laparoscopic IPAA. The main hypothesis to be tested was that laparoscopic IPAA would have a faster postoperative recovery during the first 3 months following surgery. The main metric used to evaluate postoperative recovery was intentionally based on quality of life assessments, as the authors postulated that hospital discharge is an endpoint which can be influenced by many subjective factors. This study was powered based on the assumption that a $20 \%$ difference in quality of life would be clinically significant. A Pfannenstiel incision was initially created and the sigmoid colon was mobilized through this incision. After insertion of the hand port, laparoscopic colectomy was completed using the hand-assisted technique. Transection of the terminal ileum was performed using an 
endostapler. Following complete colonic mobilization the hand port was removed and the proximal rectum was transected through the Pfannenstiel incision to remove the abdominal colon. The rectum was then dissected, distally transected, and removed using the Pfannenstiel incision followed by double- stapled IPAA. In both the laparoscopic hand-assisted and open procedures a diverting loop ileostomy was created at the surgeon's discretion. Both groups received patient-controlled analgesia and then transitioned to narcotic medications with formal pain score evaluations. In patients who were not diverted, a Foley catheter was inserted transanally into the pouch for 5 days and patients were allowed to have only clear liquids during this period to prevent obstruction of the pouch catheter with more formed stools. After 5 days the catheter was removed and the diet was further advanced. The patients were discharged when they had acceptable stool frequency and could tolerate a normal diet. Quality of life was assessed using SF-36 and a GIQLI questionnaire, ${ }^{42}$ which are recognized quality of life assessment tools. Not surprisingly, operative times were longer after laparoscopic procedures by $\sim 90$ minutes when compared with open counterparts. Morbidity was reported as divided into minor and major complications, none of which was statistically different between the 2 groups. The median hospital stay of 10 days after laparoscopic procedures was 1 day shorter than after open IPAA, but this did not reach statistical significance. Similarly, there was an equally significant decline in quality of life in the first 2 weeks after surgery regardless of the surgical approach used. However, quality of life parameters returned to baseline 4 weeks postoperatively and continued improving up to 3 months after surgery when compared with quality of life before surgery, but this was again not different between the 2 groups. Costs were not significantly increased after laparoscopic surgery. The European health care environment and the trial design do not make the results from this study easily and entirely applicable to contemporary American practices. However, this study provides methodologically strong data in the evaluation of laparoscopic versus open IPAA. Results from this study confirm safety of the laparoscopic approach but do not indicate striking benefits in recovery parameters, costs, or quality of life.

The design of another planned prospective randomized trial has been published in $2006 .{ }^{53}$ The LapConPouch-Trial has been designed as a randomized controlled, single-center, "expertise-based" trial on patients undergoing primary elective restorative proctocolectomy. The two groups under investigation should include totally laparoscopic IPAA versus open IPAA and have been powered at 80 patients per group. The primary endpoints are the assessment of differences in intraoperative blood loss and need for perioperative blood transfusions. The selection of these endpoints was based on the results from the investigators' institution indicating that laparoscopic-assisted IPAA with the rectal dissection performed through the extraction site had comparable results to the open procedures based on these specific parameters. Secondary endpoints will include postoperative morbidity, formal measurements of postoperative pain and lung function, recovery parameters including length of hospital stay and quality of life, all of which will be assessed up to 12 months postoperatively. The expected duration of the trial was planned to be 4 years with patient accrual starting in September 2004. However, the results from this trial have not yet been published.

\section{LAPAROSCOPIC TOTAL PROCTOCOLECTOMY WITH END ILEOSTOMY}

Laparoscopic surgery is also a feasible option for those patients who need a total proctocolectomy with creation of an end ileostomy. ${ }^{54}$ This subgroup includes elderly, infirm patients, patients with significant comorbidities and in general patients with poor sphincter tone for a variety of reasons. Furthermore, some younger, fitter individuals can make an informed decision not to have a restorative procedure performed once aware of the expected functional results and limitations of IPAA. In addition, some cases of low rectal carcinomas complicating ulcerative colitis are not suitable for an oncologically radical sphincter-saving procedure. In many of these patients, the perineal wound can be used as an extraction site. In the absence of a malignancy requiring a wider perineal excision, the laparoscopic procedure can be completed with perineal removal of the specimen after intersphincteric proctectomy, so that no major abdominal or perineal incisions are necessary. ${ }^{55}$

\section{CONCLUSIONS}

Several studies have demonstrated that laparoscopic ileal pouch anal anastomosis is safe and feasible, at least in experienced hands. Recovery advantages have been demonstrated by many series, but they have not been consistent in every center. On the other hand, functional results have been comparable to open surgery, although long-term functional outcomes are still not available. Therefore, equivalence in long-term functional results remains to be demonstrated. In addition, some other possible benefits of laparoscopic surgery such as reduction in overall costs have also not been consistently reported for laparoscopic IPAA. Surgeons with adequate training in complex laparoscopic surgery are attracted to laparoscopic surgery, largely because of the data reported for laparoscopic resection for colon cancer. In most cases, some of the concerns regarding cancer dissemination do not exist for inflammatory bowel disease which could potentially increase the popularity of laparoscopic total 
abdominal colectomy and IPAA. However, further investigation on the role of laparoscopic surgery for ulcerative colitis is needed. Future studies with larger populations and longer follow-up should particularly focus on recovery parameters, quality of life, and costs to assess the extent of the benefits attributed to laparoscopic surgery for ulcerative colitis.

\section{REFERENCES}

1. Truelove SC, Witts LJ. Cortisone in ulcerative colitis; final report on a therapeutic trial. BMJ 1955;2(4947):1041-1048

2. Hanauer SB. Inflammatory bowel disease. N Engl J Med 1996;334(13):841-848

3. Selvasekar CR, Cima RR, Larson DW, et al. Effect of infliximab on short-term complications in patients undergoing operation for chronic ulcerative colitis. J Am Coll Surg 2007;204(5):956-962; discussion 962-963

4. Mor IJ, Vogel JD, da Luz Moreira A, Shen B, Hammel J, Remzi FH. Infliximab in ulcerative colitis is associated with an increased risk of postoperative complications after restorative proctocolectomy. Dis Colon Rectum 2008;51(8):1202-1207; discussion 1207-1210

5. Schluender SJ, Ippoliti A, Dubinsky M, et al. Does infliximab influence surgical morbidity of ileal pouch-anal anastomosis in patients with ulcerative colitis? Dis Colon Rectum 2007;50(11):1747-1753

6. Kunitake H, Hodin R, Shellito PC, Sands BE, Korzenik J, Bordeianou L. Perioperative treatment with infliximab in patients with Crohn's disease and ulcerative colitis is not associated with an increased rate of postoperative complications. J Gastrointest Surg 2008;12(10):1730-1736; discussion 1736-1737

7. Ferrante M, D'Hoore A, Vermeire S, et al. Corticosteroids but not infliximab increase short-term postoperative infectious complications in patients with ulcerative colitis. Inflamm Bowel Dis 2009;15(7):1062-1070

8. Coquet-Reinier B, Berdah SV, Grimaud JC, et al. Preoperative infliximab treatment and postoperative complications after laparoscopic restorative proctocolectomy with ileal pouch-anal anastomosis: a case-matched study. Surg Endosc 2010;24(8):1866-1871

9. Ooi BS, Remzi FH, Fazio VW. Turnbull-Blowhole colostomy for toxic ulcerative colitis in pregnancy: report of two cases. Dis Colon Rectum 2003;46(1):111-115

10. Dunker MS, Bemelman WA, Slors JF, van Hogezand RA, Ringers J, Gouma DJ. Laparoscopic-assisted vs open colectomy for severe acute colitis in patients with inflammatory bowel disease (IBD): a retrospective study in 42 patients. Surg Endosc 2000;14(10):911-914

11. Marcello PW, Milsom JW, Wong SK, Brady K, Goormastic M, Fazio VW. Laparoscopic total colectomy for acute colitis: a case-control study. Dis Colon Rectum 2001;44(10):14411445

12. Seshadri PA, Poulin EC, Schlachta CM, Cadeddu MO, Mamazza J. Does a laparoscopic approach to total abdominal colectomy and proctocolectomy offer advantages? Surg Endosc 2001;15(8):837-842

13. Marceau C, Alves A, Ouaissi M, Bouhnik Y, Valleur P, Panis Y. Laparoscopic subtotal colectomy for acute or severe colitis complicating inflammatory bowel disease: a case-matched study in 88 patients. Surgery 2007;141(5):640-644

14. Ouaïssi M, Lefevre JH, Bretagnol F, Alves A, Valleur P, Panis Y. Laparoscopic 3-step restorative proctocolectomy: comparative study with open approach in 45 patients. Surg Laparosc Endosc Percutan Tech 2008;18(4):357-362

15. Watanabe K, Funayama Y, Fukushima K, Shibata C, Takahashi K, Sasaki I. Hand-assisted laparoscopic vs. open subtotal colectomy for severe ulcerative colitis. Dis Colon Rectum 2009;52(4):640-645

16. Telem DA, Vine AJ, Swain G, et al. Laparoscopic subtotal colectomy for medically refractory ulcerative colitis: the time has come. Surg Endosc 2010;24(7):1616-1620

17. Maartense S, Dunker MS, Slors JF, Gouma DJ, Bemelman WA. Restorative proctectomy after emergency laparoscopic colectomy for ulcerative colitis: a case-matched study. Colorectal Dis 2004;6(4):254-257

18. Holubar SD, Larson DW, Dozois EJ, Pattana-Arun J, Pemberton JH, Cima RR. Minimally invasive subtotal colectomy and ileal pouch-anal anastomosis for fulminant ulcerative colitis: a reasonable approach? Dis Colon Rectum 2009;52(2):187-192

19. McAllister I, Sagar PM, Brayshaw I, Gonsalves S, Williams GL. Laparoscopic restorative proctocolectomy with and without previous subtotal colectomy. Colorectal Dis 2009;11(3): 296-301

20. da Luz Moreira A, Kiran RP, Lavery I. Clinical outcomes of ileorectal anastomosis for ulcerative colitis. Br J Surg 2010; 97(1):65-69

21. Lefevre JH, Bretagnol F, Ouaïssi M, Taleb P, Alves A, Panis Y. Total laparoscopic ileal pouch-anal anastomosis: prospective series of 82 patients. Surg Endosc 2009;23(1):166-173

22. Fichera A, Silvestri MT, Hurst RD, Rubin MA, Michelassi F. Laparoscopic restorative proctocolectomy with ileal pouch anal anastomosis: a comparative observational study on longterm functional results. J Gastrointest Surg 2009;13(3): 526-532

23. Agha A, Moser C, Iesalnieks I, Piso P, Schlitt HJ. Combination of hand-assisted and laparoscopic proctocolectomy (HALP): technical aspects, learning curve and early postoperative results. Surg Endosc 2008;22(6):1547-1552

24. Marcello PW, Fleshman JW, Milsom JW, et al. Handassisted laparoscopic vs. laparoscopic colorectal surgery: a multicenter, prospective, randomized trial. Dis Colon Rectum 2008;51(6):818-826; discussion 826-828

25. Rivadeneira DE, Marcello PW, Roberts PL, et al. Benefits of hand-assisted laparoscopic restorative proctocolectomy: a comparative study. Dis Colon Rectum 2004;47(8):13711376

26. Marcello PW, Milsom JW, Wong SK, et al. Laparoscopic restorative proctocolectomy: case-matched comparative study with open restorative proctocolectomy. Dis Colon Rectum 2000;43(5):604-608

27. Boller AM, Larson DW. Laparoscopic restorative proctocolectomy for ulcerative colitis. J Gastrointest Surg 2007;11(1): 3-7

28. Hasegawa S, Nomura A, Kawamura J, et al. Laparoscopic restorative total proctocolectomy with mucosal resection. Dis Colon Rectum 2007;50(8):1152-1156

29. Bordeianou L, Hodin R. Total proctocolectomy with ileoanal J-pouch reconstruction utilizing the hand-assisted laparoscopic approach. J Gastrointest Surg 2009;13(12):2314-2320 
30. Benavente-Chenhalls L, Mathis KL, Dozois EJ, Cima RR, Pemberton JH, Larson DW. Laparoscopic ileal pouch-anal anastomosis in patients with chronic ulcerative colitis and primary sclerosing cholangitis: a case-matched study. Dis Colon Rectum 2008;51(5):549-553

31. Hochman DJ, Pemberton JH. Hand-assisted laparoscopic total proctocolectomy and ileal pouch-anal anastomosis after liver transplant for primary sclerosing cholangitis. Surg Laparosc Endosc Percutan Tech 2007;17(1):56-57

32. Ito M, Sugito M, Kobayashi A, Nishizawa Y, Tsunoda Y, Saito N. Relationship between multiple numbers of stapler firings during rectal division and anastomotic leakage after laparoscopic rectal resection. Int J Colorectal Dis 2008; 23(7):703-707

33. Araki Y, Ishibashi N, Ogata Y, Shirouzu K, Isomoto H. The usefulness of restorative laparoscopic-assisted total colectomy for ulcerative colitis. Kurume Med J 2001;48(2):99-103

34. Hashimoto A, Funayama Y, Naito H, et al. Laparoscopeassisted versus conventional restorative proctocolectomy with rectal mucosectomy. Surg Today 2001;31(3):210-214

35. Brown SR, Eu KW, Seow-Choen F. Consecutive series of laparoscopic-assisted vs. minilaparotomy restorative proctocolectomies. Dis Colon Rectum 2001;44(3):397-400

36. Larson DW, Cima RR, Dozois EJ, et al. Safety, feasibility, and short-term outcomes of laparoscopic ileal-pouch-anal anastomosis: a single institutional case-matched experience. Ann Surg 2006;243(5):667-670; discussion 670-672

37. Kienle P, Z'graggen K, Schmidt J, Benner A, Weitz J, Büchler MW. Laparoscopic restorative proctocolectomy. Br J Surg 2005;92(1):88-93

38. Zhang $\mathrm{H}, \mathrm{Hu} \mathrm{S}$, Zhang $\mathrm{G}$, et al. Laparoscopic versus open proctocolectomy with ileal pouch-anal anastomosis. Minim Invasive Ther Allied Technol 2007;16(3):187-191

39. Heise CP, Kennedy G, Foley EF, Harms BA. Laparoscopic restorative proctocolectomy with ileal S-pouch. Dis Colon Rectum 2008;51(12):1790-1794

40. Berdah SV, Mardion RB, Grimaud JC, et al. Mid-term functional outcome of laparoscopic restorative proctocolectomy: a prospective study of 40 consecutive cases. J Laparoendosc Adv Surg Tech A 2009;19(4):485-488

41. El-Gazzaz GS, Kiran RP, Remzi FH, Hull TL, Geisler DP. Outcomes for case-matched laparoscopically assisted versus open restorative proctocolectomy. Br J Surg 2009;96(5): $522-526$

42. Maartense S, Dunker MS, Slors JF, et al. Hand-assisted laparoscopic versus open restorative proctocolectomy with ileal pouch anal anastomosis: a randomized trial. Ann Surg 2004;240(6):984-991; discussion 991-992

43. Larson DW, Dozois EJ, Piotrowicz K, Cima RR, Wolff BG, Young-Fadok TM. Laparoscopic-assisted vs. open ileal pouchanal anastomosis: functional outcome in a case-matched series. Dis Colon Rectum 2005;48(10):1845-1850
44. Dunker MS, Bemelman WA, Slors JF, van Duijvendijk P, Gouma DJ. Functional outcome, quality of life, body image, and cosmesis in patients after laparoscopic-assisted and conventional restorative proctocolectomy: a comparative study. Dis Colon Rectum 2001;44(12):1800-1807

45. Larson DW, Davies MM, Dozois EJ, et al. Sexual function, body image, and quality of life after laparoscopic and open ileal pouch-anal anastomosis. Dis Colon Rectum 2008;51(4): 392-396

46. Polle SW, Dunker MS, Slors JF, et al. Body image, cosmesis, quality of life, and functional outcome of hand-assisted laparoscopic versus open restorative proctocolectomy: longterm results of a randomized trial. Surg Endosc 2007;21(8): 1301-1307

47. Dowson HM, Bong JJ, Lovell DP, Worthington TR, Karanjia ND, Rockall TA. Reduced adhesion formation following laparoscopic versus open colorectal surgery. Br J Surg 2008; 95(7):909-914

48. Indar AA, Efron JE, Young-Fadok TM. Laparoscopic ileal pouch-anal anastomosis reduces abdominal and pelvic adhesions. Surg Endosc 2009;23(1):174-177

49. Joyce MRHT, Geisler DP, Remzi FH, et al. Is laparoscopic surgery ileal pouch-anal anastomosis associated with fewer adhesions when compared with open surgery? (abstr). Dis Colon Rectum 2010;53:609

50. Duepree HJ, Senagore AJ, Delaney CP, Fazio VW. Does means of access affect the incidence of small bowel obstruction and ventral hernia after bowel resection? Laparoscopy versus laparotomy. J Am Coll Surg 2003; 197(2):177-181

51. Andersen LP, Klein M, Gögenur I, Rosenberg J. Incisional hernia after open versus laparoscopic sigmoid resection. Surg Endosc 2008;22(9):2026-2029

52. Gorgun E, Remzi FH, Goldberg JM, et al. Fertility is reduced after restorative proctocolectomy with ileal pouch anal anastomosis: a study of 300 patients. Surgery 2004;136(4): 795-803

53. Antolovic D, Kienle P, Knaebel HP, et al. Totally laparoscopic versus conventional ileoanal pouch procedure-design of a single-centre, expertise based randomised controlled trial to compare the laparoscopic and conventional surgical approach in patients undergoing primary elective restorative proctocolectomy-LapConPouch-Trial. BMC Surg 2006;6:13

54. Holubar SD, Privitera A, Cima RR, Dozois EJ, Pemberton JH, Larson DW. Minimally invasive total proctocolectomy with Brooke ileostomy for ulcerative colitis. Inflamm Bowel Dis 2009;15(9):1337-1342

55. Larson DW, Dozois E, Sandborn WJ, Cima R. Total laparoscopic proctocolectomy with Brooke ileostomy: a novel incisionless surgical treatment for patients with ulcerative colitis. Surg Endosc 2005;19(9):1284-1287 